\title{
Machine learning and HEC-RAS integrated models for flood inundation mapping in Baro River Basin, Ethiopia
}

\author{
Habtamu Tamiru ${ }^{1}$ \\ ${ }^{1}$ Wollega University
}

February 10, 2021

\begin{abstract}
This paper presents the integrated machine learning and HEC-RAS models for flood inundation mapping in Baro River Basin, Ethiopia. A predictive rainfall-runoff and spatially distributed river simulation models were developed using Artificial Neural Networks (ANNs) and HEC-RAS respectively. Daily rainfall and temperature data of 7-yrs and Topographical Wetness Index (TWI) with a spatial resolution of $50 \times 50 \mathrm{~m}$ were used to train the ANN in R studio. The integration of the spatial and temporal variability in this paper improved the accuracy of the predictive models integrated with ANN and HEC-RAS. The predictive ANN model was tested with the observed daily discharge of the same temporal resolution and the rainfall-runoff result obtained from the tested ANN model was used as input for the HEC-RAS. The flood event of 2005 was used to verify the accuracy of flood generated in the HEC-RAS model by implementing the Normal Difference Water Index (NDWI). The comparison was made between the flood inundation map generated by HEC-RAS and flood events of different periods based on coverage percentage areas and a good agreement was reached with $96 \%$ overlapped areas. The performance of ANN and HEC-RAS models were evaluated with 0.86 and 0.88 values at the training and testing period respectively. Finally, it was concluded that the integration of a machine learning approach with the HEC-RAS model in developing a flood inundation mapping is an appropriate tool to warn residents in this river basin.
\end{abstract}

\section{Hosted file}

ANN.pdf available at https://authorea.com/users/394893/articles/508221-machine-learning-andhec-ras-integrated-models-for-flood-inundation-mapping-in-baro-river-basin-ethiopia 